\title{
Geodermatophilaceae fam. nov., a formal description
}

\author{
Philippe Normand
}

Correspondence

Philippe Normand

normand@biomserv.univ-lyon1.fr

\author{
UMR 5557 CNRS Ecologie Microbienne, IFR41 Bio-Environnement et Santé, Université \\ Lyon 1, 43 Bd du 11 Novembre 1918, 69622 Villeurbanne Cedex, France
}

\begin{abstract}
The family name 'Geodermatophilaceae' was first published by Normand et al. (1996) to contain the genera Geodermatophilus and Blastococcus, but a formal description and the designation of the type genus were not included, thus making the name invalid. Since then, the genus Modestobacter has been described as a member of the family 'Geodermatophilaceae' by Mevs et al. (2000). We hereby formally describe the family 'Geodermatophilaceae' which includes the recently described genus Modestobacter. The type genus of the family is Geodermatophilus.
\end{abstract}

In Bergey's Manual of Systematic Bacteriology, Lechevalier (1989) grouped the genera Geodermatophilus, Dermatophilus and Frankia in the section 'Actinomycetes with multilocular sporangia'. These three genera share the remarkable morphological feature of the formation of sporangia of up to $100 \mu \mathrm{m}$ in diameter that divide in all three planes. A few years before, Ahrens \& Moll (1970) isolated and described a bacterium from the Baltic sea that formed budding structures, Blastococcus aggregatus. Recently, Urzi et al. (2004) published an emended description of genus Blastococcus and the genus now comprises two species, Blastococcus aggregatus and Blastococcus saxobsidens. Using 16S rRNA gene sequences, Hahn et al. (1989) showed that the genus Dermatophilus was only distantly related to the genus Geodermatophilus and that the genera Geodermatophilus, Blastococcus and Frankia were indeed closely related and proposed an emended description of the family Frankiaceae to include these three genera.

The family 'Geodermatophilaceae' was initially proposed by Normand et al. (1996) to contain the genera
Geodermatophilus and Blastococcus that were previously assigned to the family Frankiaceae, and which thus retained only one genus, Frankia. No formal description of the family was provided and the type genus was not designated, therefore the family was not considered to be validly published. Stackebrandt et al. (1997) emended the description of the family by describing signature nucleotides and assigning the genus Geodermatophilus as the type genus for the family, but since the original description was not valid, the emended description was also not valid.

A phylogenetic analysis based on 16S rRNA gene sequences shows the family 'Geodermatophilaceae' to be highly coherent with a bootstrap value of $100 \%$ and to have the genera Frankia and Acidothermus as its closest neighbours (Fig. 1). The morphological, chemotaxonomic and physiological characteristics of the family are given in Table 1.

\section{Description of Geodermatophilaceae fam. nov.}

Geodermatophilaceae (Geo.der.ma.to.phi.la'ce.ae. N.L. masc. n. Geodermatophilus type genus of the family; suff.

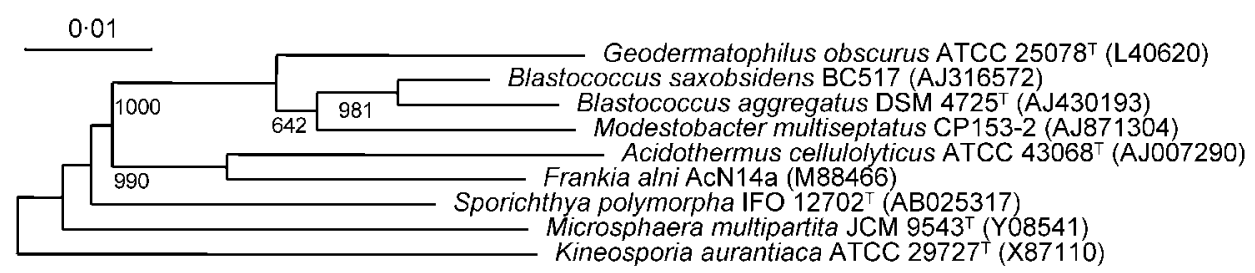

Fig. 1. Phylogenetic tree showing representatives of the three genera and recognized species of the family 'Geodermatophilaceae', together with representatives of the type species of the genera in the Frankineae. 16S rRNA gene sequences were aligned using CLUSTAL_X (Thompson et al., 1997). Indel-containing regions were excluded from the analysis. Matrix pairwise comparisons were corrected for multiple base substitutions by the method of Kimura (1980). The tree was constructed by the neighbour-joining method (Saitou \& Nei, 1987). A bootstrap confidence analysis was performed on 1000 replicates to determine the reliability of the tree topologies obtained (Felsenstein, 1985). Bootstrap values are shown at branch points. The graphic representation of the resulting tree was constructed using NJPLOT software (Perrière \& Gouy, 1996). Bar, 0.01 nucleotide substitutions per site. 
Table 1. Characteristics of the three genera of the family 'Geodermatophilaceae'

Data are from Mevs et al. (2000), Urzi et al. (2004) and Lechevalier (1989). +, Positive/present; -, negative/not present.

\begin{tabular}{|c|c|c|c|}
\hline Characteristic & Geodermatophilus & Blastococcus & Modestobacter \\
\hline \multicolumn{4}{|l|}{ Morphology } \\
\hline Hyphae & Rudimentary & - & - \\
\hline Spores & Motile & Motile & Motile \\
\hline Sporangia & + & - & - \\
\hline Buds & - & + & + \\
\hline Colony colour & White, red, black & Pink, orange & White, pink, black \\
\hline \multicolumn{4}{|l|}{ Physiology } \\
\hline Requirement for $\mathrm{O}_{2}$ & Aerobic & Aerobic/microaerophilic & Aerobic \\
\hline Temperature range $\left({ }^{\circ} \mathrm{C}\right)$ & $18-37$ & $3-40$ & $0-28$ \\
\hline Temperature optimum $\left({ }^{\circ} \mathrm{C}\right)$ & $24-28$ & 25 & $19-21$ \\
\hline Tolerance of $3 \% \mathrm{NaCl}$ & - & + & + \\
\hline Hydrolysis of starch & + & - & - \\
\hline D-Glucose & + & - & + \\
\hline \multicolumn{4}{|l|}{ Chemistry } \\
\hline Menaquinone & MK-9 $\left(\mathrm{H}_{4}\right)$ & MK-9 $\left(\mathrm{H}_{4}\right)$ & MK-9 $\left(\mathrm{H}_{4}\right)$ \\
\hline DNA G $+C(\operatorname{mol} \%)$ & $73-75$ & 74 & 70 \\
\hline Habitat & Soil, rock surfaces & Rock surfaces, sea & Polar 'soil' \\
\hline
\end{tabular}

-aceae ending to denote a family; N.L. fem. pl. n. Geodermatophilaceae the Geodermatophilus family).

Exhibits the following properties in addition to those given in the family description by Stackebrandt et al. (1997). Includes rods or rudimentary hyphae. Motile spores. Colonies are red- or black-pigmented. Aerobic growth. MK-9 $\left(\mathrm{H}_{4}\right)$ menaquinones are present. DNA G $+\mathrm{C}$ content is between 70 and $75 \mathrm{~mol} \%$. 16S rRNA nucleotide signatures are 139-224 (C-G), 157-164 (A-U), 158-163 (A-U), 186-191 (C-G), 263 (G), 293-304 (G-U), 986-1219 (U-A), 987-1218 (A-U), 1059-1198 (U-A) and 13081329 (U-A) with the specific motif CaGCTCTGGGATAACTCCAAGAAATT at coordinates 139-165 in the 16S rRNA gene. Habitat ranges from dry soils and rock surfaces to seawater. The family Geodermatophilaceae contains the genera Geodermatophilus, Blastococcus and Modestobacter.

The type genus is Geodermatophilus (Luedemann, 1968).

\section{Acknowledgements}

Thanks are expressed to Dr Jean Euzéby (ENVT, Toulouse, France) and David Labeda (USDA, Peoria, IL, USA) for advice.

\section{References}

Ahrens, R. \& Moll, G. (1970). Ein neues knospendes Bakterium aus der Ostsee. [A new budding bacterium from the Baltic Sea]. Arch Mikrobiol 70, 243-265.

Felsenstein, J. (1985). Confidence limits on phylogenies: an approach using the bootstrap. Evolution 39, 783-791.

Hahn, D., Lechevalier, M. P., Fischer, A. \& Stackebrandt, E. (1989). Evidence for a close phylogenetic relationship between members of the genera Frankia, Geodermatophilus, and "Blastococcus" and emendation of the family Frankiaceae. Syst Appl Microbiol 11, 236-242.

Kimura, M. (1980). A simple method for estimating evolutionary rates of base substitutions through comparative studies of nucleotide sequences. J Mol Evol 16, 111-120.

Lechevalier, M. P. (1989). Actinomycetes with multilocular sporangia. In Bergey's Manual of Systematic Bacteriology, Vol. 4, pp. 2405-2410. Edited by S. T. Williams, M. E. Sharpe \& J. E. Holt. Baltimore: Williams \& Wilkins.

Luedemann, G. M. (1968). Geodermatophilus, a new genus of the Dermatophilaceae (Actinomycetales). J Bacteriol 96, 1848-1858.

Mevs, U., Stackebrandt, E., Schumann, P., Gallikowski, C. A. \& Hirsch, P. (2000). Modestobacter multiseptatus gen. nov., sp. nov., a budding actinomycete from soils of the Asgard Range (Transantarctic Mountains). Int J Syst Evol Microbiol 50, 337-346.

Normand, P., Orso, S., Cournoyer, B., Jeannin, P., Chapelon, C., Dawson, J., Evtushenko, L. \& Misra, A. K. (1996). Molecular phylogeny of the genus Frankia and related genera and emendation of the family Frankiaceae. Int J Syst Bacteriol 46, 1-9.

Perrière, G. \& Gouy, M. (1996). WWW-query: an on-line retrieval system for biological sequence banks. Biochimie 78, 364-369.

Saitou, N. \& Nei, M. (1987). The neighbor-joining method: a new method for reconstructing phylogenetic trees. Mol Biol Evol 4, 406-425.

Stackebrandt, E., Rainey, F. A. \& Ward-Rainey, N. L. (1997). Proposal for a new hierarchic classification system, Actinobacteria classis nov. Int J Syst Bacteriol 47, 479-491.

Thompson, J. D., Gibson, T. J., Plewniak, F., Jeanmougin, F. \& Higgins, D. G. (1997). The CLUSTAL_X windows interface: flexible strategies for multiple sequence alignment aided by quality analysis tools. Nucleic Acids Res 25, 4876-4882.

Urzi, C., Salamone, P., Schumann, P., Rohde, M. \& Stackebrandt, E. (2004). Blastococcus saxobsidens sp. nov., and emended descriptions of the genus Blastococcus Ahrens and Moll 1970 and Blastococcus aggregatus Ahrens and Moll 1970. Int J Syst Evol Microbiol 54, 253-259. 